\title{
Organic side streams: using microbes to make substrates more fit for mass producing insects for use as feed
}

\author{
J.B. Zhang ${ }^{1 *}$, Y.Q. Yu ${ }^{1}$, J.K. Tomberlin ${ }^{2}$, M.M. Cai ${ }^{1}$, L.Y. Zheng ${ }^{1}$ and Z.N. Yu ${ }^{1}$ \\ ${ }^{1}$ State Key Laboratory of Agricultural Microbiology, College of Life Science and Technology, Huazhong Agricultural University, \\ Wuhan, 430070, China P.R.; ${ }^{2}$ Department of Entomology, Texas A\&M University, 2475 TAMU, College Station, TX 77843, \\ USA;zhangjb@mail.hzau.edu.cn
}

Received: 11 July 2020 / Accepted: 12 October 2020

(c) 2021 Wageningen Academic Publishers

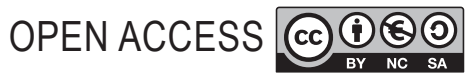

REVIEW ARTICLE

\begin{abstract}
Microbes, combined with insects, convert organic waste into products of value. Resulting insects can be harvested and used as a high-quality protein resource, while the residues can be used as fertiliser. Microbes play an important role in the conversion process. This review's aim was focused on how microbes promote insects such as black soldier fly (Hermetia illucens L.), house fly (Musca domestica L.), waxworm (Plodia interpunctella) and yellow meal worm (Tenebrio molitor L.), to convert organic waste, while also harmlessly reducing organic waste pollution. The novelty is reflected in some core gut microbiota and their secreted enzymes degrade macromolecules such as protein, fat, polysaccharide, cellulose, polystyrene and polyethylene. Gut microbiota also could help insects degrade hazardous substances such as antibiotics, mycotoxin, odorous substances, and inhibit pathogens in organic wastes to make substrates more fit for insects.
\end{abstract}

Keywords: insects, gut microbiota, organic waste, conversion, degradation

\section{Introduction}

Globally, approximately 1.6 billion tons of food waste are generated annually (Ma et al., 2020). However, due to challenges with collecting these materials, only a portion of the food waste is being treated. Such practices (i.e. not recycling such materials) pose environmental and economic concerns (Salihoglu et al., 2018), as well as human health hazards (Sindhu et al., 2019). Other common organic wastes are livestock and poultry manure. According to the forecast of the demographic website (https://populationstat.com/), the global human population will reach 9.7 billion by 2050 . Such growth will inevitably increase the demand for food, especially livestock and poultry products, which will increase the amount of livestock and poultry manure. Livestock and poultry manures are rich in nitrogen, phosphorus, and potassium (Dróżdż et al., 2020). Unfortunately, large amounts of livestock and poultry manures are not treated or utilised properly potentially leading to eutrophication and soil degradation (Qian et al., 2018).
Plastics in association with food production are also being mass produced and resulting in additional environmental concerns. Data from the Ministry of Agriculture and Rural Affairs of the People's Republic of China show that the use of agricultural plastic films nationwide reached 2.593 million tons in 2016. During the past 30 years, residual pollution of plastic film has become a serious issue worldwide. Plastic film remaining in the soil is difficult to degrade, and it will also lead to the reduction of crop production (Yan et al., 2016).

Currently, pollution issues resulting from the previously described organic waste concerns demonstrate the need for sustainable methods of remediation. Using insects to convert organic wastes into products of value can be achieved. Furthermore, integrating microbes as part of the process could enhance efficiency of such systems (Xiao et al., 2018). The gut microbiome of insects and microbiota in organic waste are now being harnessed as a means to increase the ability of mass produced insects to recycle these materials. 


\section{Microbe enhanced conversion efficiency and insect growth}

A number of insect species are used to digest the wastes previously described. The primary species are black soldier fly (BSF; Hermetia illucens L.), house fly (HF; Musca domestica L.) and yellow mealworm (YMW; Tenebrio molitor L.) (Čičková et al., 2015).

Black soldier fly larvae (BSFL) convert different organic wastes, and while the structure of its gut microbes shift depending on diet, Firmicutes and Proteobacteria have been identified as the core phyla (Wynants et al., 2019; Zhan et al., 2020). These phyla may play an important role in promoting the ability of the BSFL to convert organic waste into biomass. For example, BSFL gut microbes produce carbohydrate-active enzymes that significantly enhance this process (Jiang et al., 2019). Studies have confirmed that Firmicutes can secrete a variety of proteases and pectinases, allow the BSFL to digest animal faeces as well as indigestible carbohydrates in straw-related compost (Sun et al., 2015; Zhang et al., 2018).

Gastrointestinal morphology of the BSFL plays an important role in shaping microbial load and diversity (Bruno et al., 2019). Microbial diversity is greatest in the midgut and then gradually decreases towards the posterior regions. However, bacterial load was greatest in the posterior region. Xylanases produced by Bacteroidetes, one of the dominant phyla in BSFL gut directly involved in hemicellulose digestion (Bruno et al., 2019).

Bacillus and associated yeasts are in high abundance in the BSFL intestine (De Smet et al., 2018; Zhan et al., 2020). Bacillus can degrade lignocellulose, while yeasts utilise metabolites and accumulate protein and polysaccharide ( $\mathrm{Li}$ et al., 2016). Rehman developed an efficient co-digestion strategy for using BSFL to treat dairy manure (DM) when mixed with an appropriate proportion of chicken manure $(\mathrm{CHM})$ or soybean curd to reaching nutrition $(\mathrm{C} / \mathrm{N}$ ratio) balance and buffering capacity $(\mathrm{pH})$ of the animal wastes (ur Rehman et al., 2017a,b). Furthermore, adding exogenous probiotics resulted in higher bioconversion efficacy (10.8\%), survival rate (99.1\%), food conversion ratio (4.5), manure reduction rate (48.7\%), and fibre content reduction (cellulose; $72.9 \%$, hemicellulose; 68.5\%, lignin; $32.8 \%$ ), than relying on associated gut microbiota alone. Analysis of the fibre structural and chemical changes with scanning electron microscopy and Fourier-transformed infrared spectroscopy indicates the structure and chemical composition of the fibre had been modified. The surface morphology of fibres of DM40:CHM60 when pre-treated with exogenous probiotics was relatively compact and rigid before BSFL digestion, but after digestion the material was porous and more corrugated. The degraded effects in the chemical composition of the fibre were more obvious in the treatment when BSFL were assisted with microbes (ur Rehman et al., 2019). Clearly, microbes play an important role in the conversion of organic waste, by adding microbes to organic waste, the ability of insect hosts to degrade organic waste can be improved (Table 1). The HF also could convert animal manure (Van Huis et al., 2013). Conversion of $\mathrm{HF}$ also defined as a microbial-driven process, which was dominated by Entomoplasma somnilux, Proteobacterium, and Clostridiaceae bacterium (Zhang et al., 2012).

Waxworm (WW) (Yang et al., 2014) and YMW (Zhang et al., 2017) can degrade plastic wastes. Two bacterial strains capable of degrading polyethylene (PE) were isolated from the gut of WM, Enterobacter asburiae YT1 and Bacillus sp. YP1. Over a 60-day incubation period of the two strains with PE film degraded PE with approximately $6.1 \pm 0.3$ and $10.7 \pm 0.2 \%$ (Yang et al., 2014). When degrading polystyrene (PS) and PE, it was found that Citrobacter sp. and Kosakonia sp. in the gut of YMW are closely related to the degradation of PE and PS (Brandon et al., 2018). The dominant strains in the YMW gut are mainly Enterobacter, Lactococcus and Enterococcus. The strains with biodegradable activity Klebsiella, Pseudomonas and Serratia were isolated from YMW digesting plastics (Urbanek et al., 2020). The potential to enrich these strains in vitro, and then combined with the insect could enhance plastic degradation. Furthermore, by changing the diet of YMW, the microbial community structure in its gut could be shifted, thereby improving the efficiency of PS degradation (Peng et al., 2019). Super worm (Zophobas atratus) can also degrade PS. Inoculating diet with antibiotics was found to inhibit associated gut microbes and the ability of the insect to degrade PS demonstrating the gut microbes play a role in such processes (Yang et al., 2020). We speculated some gut microbes in WW and YMW could produce special emzymes to degrade the plastics such as PE and PS. The mechanism should be further explored.

Bacteria from other insects are known to play a role in host metabolism. Acetobacter pomorum, which was isolated from Drosophila (Diptera: Drosophilidae), has obvious growth promoting effect (Kim et al., 2020). A. pomorum WJL (ApWJL) and Lactobacillus plantarum NC8 (LpNC8) can promote the growth of Drosophila larvae by shifting nutritional requirements of the host (Consuegra et al., 2020). A. pomorum regulates insulin/ insulin-like growth factor signal through its pyroquinoline quinone ethanol dehydrogenase to regulate host intestinal homeostasis, which controls host development rate and energy metabolism (Shin et al., 2015). L. plantarum promotes systemic development of Drosophila by regulating hormone growth signals through the host nutrition sensing system dependent on target of rapamycin (Storelli et al., 2011). Acetic acid, a metabolite of $L$. plantarum, binds to the diaminopropionic acid-type peptidoglycan-sensitive receptor PGRP-LC in the innate immune pathway of Drosophila-immune deficiency pathway, which stimulates 
Table 1. Black soldier fly larvae (BSFL) combined with microbes to convert organic waste.

\begin{tabular}{|c|c|c|c|c|}
\hline Substrate & Microbe source & $\begin{array}{l}\text { Organic waste reduction } \\
\text { rate }(\%) \text { compared with } \\
\text { the control group }\end{array}$ & $\begin{array}{l}\text { Larval weight gain rate } \\
(\%) \text { compared with the } \\
\text { control group }\end{array}$ & References \\
\hline Chicken manure & Bacillus subtilis BSF-CL & 13.4 & 15.9 & Yu et al. (2011) \\
\hline Chicken manure & B. subtilis BSF-CL (from gut bacteria) & 12.7 & 15.9 & Xiao et al. (2018) \\
\hline $\begin{array}{l}\text { Dairy and chicken } \\
\text { manure mixed }\end{array}$ & $\begin{array}{l}\text { Exogenous bacteria (from soil and pig } \\
\text { manure fermentation products) }\end{array}$ & $0.6-16.2$ & $7.99-16.7$ & ur Rehman et al. (2019) \\
\hline Soybean curd residue & $\begin{array}{l}\text { Lactobacillus buchneri L3-9 (from } \\
\text { Microbial Pesticide Key State } \\
\text { Laboratory of HZAU) }\end{array}$ & $13.6-26.9$ & $15.8-23.5$ & Somroo et al. (2019) \\
\hline Chicken manure & $\begin{array}{l}\text { Companion bacteria (from the egg } \\
\text { surface of BSF within } 6 \text { hours after } \\
\text { spawning, and from the gut of } 5^{\text {th }} \\
\text { instar larvae) }\end{array}$ & $0.9-7.2$ & $5.79-28.57$ & Mazza et al. (2020) \\
\hline \multirow[t]{2}{*}{ Banana peel } & $\begin{array}{l}\text { Trichoderma reesei and Rhizopus } \\
\text { oligosporus (from the Department of } \\
\text { Molecular Sciences, SLU) }\end{array}$ & $25.7-33.9$ & $26.1-58.9$ & Isibika et al. (2019) \\
\hline & $\begin{array}{l}\text { A mixture of bacteria (from the BSFL } \\
\text { gut) }\end{array}$ & 4.3 & 6.7 & \\
\hline
\end{tabular}

the endocrine peptide tachykinin. Transcription, thereby optimising Drosophila lipid metabolism and activating insulin signals, promoting the growth and development of Drosophila larvae (Kamareddine et al., 2018). Honey bee (Apis mellifera) gut microbes promote the growth of the host through the regulation of metabolites (Zheng et al., 2017). Bifidobacterium and Gilliamella are the principal degraders of hemicellulose and pectin in the honey bee larval gut, providing nutrients for the host to promote growth (Zheng et al., 2019). Sterile BSFL without gut microbe are impaired; however, after adding its gut microbe, such as Bacillus subtilis BSF-CL, BSFL growth and associated chicken manure conversion can be improved. The gut microbes of BSF can not only promote the growth of the host, but also improve the efficiency of the host to convert organic waste (Table 1).

\section{Microbes help insect in antibiotic-resistant attenuation and antibiotics degradation}

Using antibiotics as prophylaxis for poultry poses serious threat to human health due to resulting manure used as fertility spreading antibiotic-resistant bacteria (Tyrrell et al., 2019). Antibiotic resistance genes (ARGs) can be transmitted from animal products or the environment to people (Landers et al., 2012; Muloi et al., 2018). In agriculture, manure and sludge are often used to increase crop yields, which is a key enabler of resistance gene flow into an ecosystem (Kivits et al., 2018; Udikovic-Kolic et al., 2014). Approximately $58 \%$ of veterinary antibiotics are transferred to the environment with most being introduced to soil through resulting manure used as a fertiliser (Xie et $a l ., 2018)$. Among the compost products of livestock and poultry manure, the potential bacterial hosts of ARGs are actinomycetes, such as Leucobacter, Mycobacterium and Thermomonosporaceae (Zhang et al., 2020).

Developing methods to remediate ARGs in manure is crucial. Microbes in combination with insects, such as the BSFL, could be used to mitigate ARGs risk. For example, BSFL treatments could effectively reduce antibiotic resistance genes in chicken manure by $95.0 \%$. Previous research has determined BSFL intestinal microbiota serve as a major mechanism regulating these processes (Cai et al., 2018a). How the BSFL intestinal microbiota interact with their host to mitigate ARGs should be further explored. Furthermore, BSFL are capable of directly degrading antibiotics, such as tetracycline (TC) in chicken manure. Nearly $97 \%$ of TC was degraded within 12 days by BSFL. The gut microbiota of the BSFL plays a significant role in degrading TC, effectively and rapidly (Cai et al., 2018b). How the BSFL intestinal microbiota interact with their host to degrading antibiotics also should be further explored. Similarly, swine manure digestion by HF larvae is a promising method for manure reduction and associated ARGS as well. Previous research determined 94 out of 158 ARGs were significantly mitigated (by $85 \%$ ) following the conversion. ARG attenuation was significantly correlated with changes in the relative abundances of the family Ruminococcaceae, class bacilli, or phylum Proteobacteria and microbial community, especially reduction in Clostridiales and Bacteroidales (Wang et al., 2015, 2017). 
HF larvae also can degrade antibiotics. Previous research determined HF larvae could degrade monensin in chicken manure by increasing the number of Stenotrophomonas sp. and Alcaligenes sp. in the larval gut (Li et al., 2019a). If insect larvae are combined with microbes, such as Classes Gammaproteobacteria, Bacteroidia, and Betaproteobacteria, and Klebsiella sp. SQY5, etc., to reduce antibiotics in organic waste, degradation efficiency may be improved. House fly larvae convert a mixture of swine manure and gibberellin fermentation residues (GFRs). The concentration of gibberellin in the converted residue decreased significantly, and with the increase of GFRs in the mixture, Bacillus became the dominant bacteria, indicating that Bacillus can promote gibberellin degradation (Yao et al., 2020). There is already evidence that Corynebacterium variabile Q0029 combined with HF larvae can promote the degradation of gibberellin (Yang et al., 2015).

\section{Microbes help insect in pathogens inhibition}

Livestock manure contain various pathogens, including bacteria, viruses, parasites, fungi, such as Salmonella spp., Escherichia coli O157:H7, Avian influenza virus, etc. (Alegbeleye and Sant'Ana, 2020). E. coli (STEC) O157:H7 in manure produces Shiga toxins that can contaminate surface water and cause haemolytic uremic syndrome in humans and animals (Tanaro et al., 2018). These manureborne pathogens pose a huge threat to public health and the environment (Spencer and Guan, 2004). Due to the expansion of livestock and poultry farming, associated manure in some instances is directly discharged into the environment without treatment, causing pathogens in the manure to threaten the safety of drinking water and cause other animals to be infected (Alegbeleye and Sant'Ana, 2020; Bicudo and Goyal, 2003; Ström et al., 2018). In the aquaculture industry, the use of untreated livestock and poultry manure not only pollutes the water, but also results in fish disease and economic loss (Wanja et al., 2020). Therefore, reducing pathogens in livestock and poultry manure is very important to public health and environment.

Insect larvae such as BSFL can significantly reduce the concentration of pathogens in swine manure and dairy manure (Erickson et al., 2004; Liu et al., 2008). Gut commensal microbes are in a competitive relationship with pathogens that enter the gut. Elimination of the commensal microbes results in pathogens proliferation and disease manifestation (Fast et al., 2018). The gut microbiota can regulate the host immune cells and enhance the gut mucosal barrier function, so that the host can establish a strong immune response against invading pathogens, and the importance of gut microbiota in regulating the immune system is mainly to maintain the homeostasis of the gut (Alarcón et al., 2016; Kogut et al., 2020; Shi et al., 2017). Insect gut microbes play an important role in maintaining gut homeostasis, and their ability to inhibit pathogenic bacteria has a positive effect on host health.

Interestingly, researchers found a novel, temperate Escherichia bacteriophage designated vB_EcoS_PHB10 (PHB10), which could lyse two out of 13 Escherichia strains tested (Chen et al. 2019). Accordingly, the BSF immune system might have adapted to mitigate pathogenic microbes. Furthermore, the genomes of BSF encode more secreted peptidoglycan recognition proteins (PGRPs) and Gram-negative binding proteins compared to those in other dipteran species. Further research found two BSF immune genes BsfDuox and BsfTLR3 could regulate the gut key bacteria Providencia and Dysgonomonas homeostasis to depress zoonotic pathogens (Huang et al. 2020). The mechanism of bacteriophage and gut key bacteria in depressing zoonotic pathogens is still unknown and need further be explored.

\section{Microbes help insect in odour removal of organic waste}

Manure emits greenhouse gases and other volatile organic compounds during the decomposition process (FAO, 2009). Volatile organic compounds, such as 4-methylphenol was responsible for $67.3 \%$ of odour activity in dairy manure (Hales et al., 2012). Processing organic waste with BSFL results in volatile fatty acids (VFAs) being reduced (Sundberg et al., 2013). VFAs are short-chain fatty acids containing six carbon atoms or less, such as acetic, propionic acid, iso-butyric acid, n-butyric acid, iso-valeric acid and n-pentanoic acid (Agler et al., 2011; Fang et al., 2016). Lactic acid and acetic acid have a higher odour threshold than butyric acid and valeric acid (Rosenfeld et al., 2007). VFAs is easily produced under anaerobic and low $\mathrm{pH}$ conditions (Liu et al., 2020; Sundberg et al., 2013).

BSFL can significantly reduce poultry, swine, and dairy manure release volatile organic compounds to the environment (Beskin et al., 2018). BSFL can reduce the accumulation of VFAs in organic wastes by $10.12-28.50 \%$. Interestingly, VFAs can be used as a carbon source for the survival of BSFL and natural microbiota (Liu et al., 2020). Use an engineering microbial ecosystem to remove odorous gas from industrial waste, before treatment, the dominant strains are genera Thiobacillus and Oceanicaulis, after treatment, the dominant strains are genera Acidithiobacillus and Ferroplasma (Li et al., 2019b). We speculated both exoand endo-symbionts inhibited the microbes that produced odorous gas.

\section{Prospects of research on the degradation of organic waste by insects and microbes}

There are many ways to deal with organic wastes. BSFL is a representative insect that converts organic wastes into products of value. After the conversion, the content of many 
organic wastes decreased by 20.31-22.18\%. Furthermore, VFAs are also decreased by $25.58-80.08 \%$. Nitrogen content in the waste also is reduced by $6.08-14.37 \%$. Total phosphorous, total Kjeldahl nitrogen, and total nutrients increased by $42.30-64.16,45.41-88.17$, and $26.51-33.34 \%$, respectively (Liu et al., 2019).

Black soldier fly larvae have broad application prospects for the treatment of livestock and poultry manure pollution. Current research is devoted to further improving the efficiency of BSFL to convert livestock and poultry manure. At present, combining BSFL and microorganisms can further improve the efficiency of BSFL converting livestock and poultry manure. Some of the microorganisms used include BSFL gut microbes, BSFL associated microorganisms (BSF egg surface microbes), and microorganisms separated from livestock and poultry manure composting (Mazza et al., 2020; Xiao et al., 2018). However, it is not clear that the mechanism of how microorganisms cooperates with BSFL to convert manure and further research is needed.

Microbes can not only improve the efficiency of insect hosts to degrade organic waste, but also promote the growth of insect hosts (Xiao et al., 2018). In particular, the mutually beneficial symbiosis between intestinal microbes and the host has always been a research hotspot. Microbes play an important role in helping the host to resist adverse environments. The gut commensal bacteria Klebsiella michiganensis BD177 stimulates the metabolic activity of arginine and proline in the host to help the host resist the low temperature environment (Raza et al., 2020). Bifidobacterium animalis enhances the host's ability to resist influenza by mediating the metabolism of valine and coenzyme A (Zhang et al., 2020).

\section{Conclusions}

Food and Agriculture Organization of the United Nations (FAO) recommended several main insects such as BSFL, HF, and YMW to treat organic wastes (Van Huis et al., 2013). They not only convert the animal manure to insect biomass, but also food waste, PS and PE. Scientists found their gut microbiota play important role in these organic side streams conversion. The novelty is reflected in that some gut microbes and their secreted enzymes degrade macromolecules such as protein, fat, polysaccharide, cellulose, PS and PE. For example, the phyla Firmicutes and Proteobacteria are main microbiota response to macromolecules degradation in organic waste. Other microbes, such as Bacillus, Enterobacter, and yeast can secrete some protease, cellulase, lipase and xylanase, and degrade the macromolecules in organic wastes into small molecules, which can be used as the nutrients of insects. Gut microbiota also could help insects degrade hazardous substances such as antibiotics, mycotoxin, odorous substances and inhibited pathogens in organic wastes. So insect gut microbiota could help their host to degrade macromolecules and hazardous substances in organic side streams and make substrates more fit for insects. But their mechanisms are not very clear and need further be explored.

\section{Acknowledgements}

This work was supported by the National Key Technology R\&D Program of China (2018YFD0500203) and National Natural Science Foundation of China (31770136).

\section{Conflict of interest}

The authors declare no conflict of interest.

\section{References}

Agler, M.T., Wrenn, B.A., Zinder, S.H. and Angenent, L.T., 2011. Waste to bioproduct conversion with undefined mixed cultures: the carboxylate platform. Trends Biotechnology 29: 70-78.

Alarcón, P., González, M. and Castro, É., 2016. Rol de la microbiota gastrointestinal en la regulación de la respuesta inmune. Revista Médica de Chile 144: 910-916.

Alegbeleye, O.O. and Sant'Ana, A.S., 2020. Manure-borne pathogens as an important source of water contamination: an update on the dynamics of pathogen survival/transport as well as practical risk mitigation strategies. International Journal of Hygiene and Environmental Health 227: 113524.

Beskin, K.V., Holcomb, C.D., Cammack, J.A., Crippen, T.L., Knap, A.H., Sweet, S.T. and Tomberlin, J.K., 2018. Larval digestion of different manure types by the black soldier fly (Diptera: Stratiomyidae) impacts associated volatile emissions. Waste Management 74: 213-220.

Bicudo, J.R. and Goyal, S.M., 2003. Pathogens and manure management systems: a review. Environmental Technology 24: 115-130.

Brandon, A.M., Gao, S., Tian, R., Ning, D., Yang, S., Zhou, J., Wu, W. and Criddle, C.S., 2018. Biodegradation of polyethylene and plastic mixtures in mealworms (larvae of Tenebrio molitor) and effects on the gut microbiome. Environmental Science \& Technology 52: 6526-6533.

Bruno, D., Bonelli, M., De Filippis, F., Di Lelio. I., Tettamanti, G., Casartelli, M., Ercolini, D. and Caccia, S., 2019. The intestinal microbiota of Hermetia illucens larvae is affected by diet and shows a diverse composition in the different midgut regions. Applied and Environmental Microbiology 85: 1-14.

Cai, M., Ma, S., Hu, R., Tomberlin, J.K., Thomashow, L.S., Zheng, L., Li, W., Yu, Z. and Zhang, J., 2018a. Rapidly mitigating antibiotic resistant risks in chicken manure by Hermetia illucens bioconversion with intestinal microflora. Environmental Microbiology 20: 40514062.

Cai, M., Ma, S., Hu, R., Tomberlin, J.K., Yu, C., Huang, Y., Zhan, S., Li, W., Zheng, L., Yu, Z. and Zhang, J., 2018b. Systematic characterization and proposed pathway of tetracycline degradation in solid waste treatment by Hermetia illucens with intestinal microbiota. Environmental Pollution 242: 634-642. 
Chen, Y., Li, X., Song, J., Yang, D., Liu, W., Chen, H., Wu, B. and Qian, P., 2019. Isolation and characterization of a novel temperate bacteriophage from gut-associated Escherichia within black soldier fly larvae (Hermetia illucens L. [Diptera: Stratiomyidae]). Archives of Virology 164: 2277-2284.

Čičková, H., Newton, G.L., Lacy, R.C. and Kozánek, M., 2015. The use of fly larvae for organic waste treatment. Waste Management 35: 68-80.

Consuegra, J., Grenier, T., Baa-Puyoulet, P., Rahioui, I., Akherraz, H., Gervais, H., Parisot, N., Da Silva, P., Charles, H., Calevro, F. and Leulier, F., 2020. Drosophila-associated bacteria differentially shape the nutritional requirements of their host during juvenile growth. PLoS Biology 18: e3000681.

Dróżdż, D., Wystalska, K., Malińska, K., Grosser, A., Grobelak, A. and Kacprzak, M., 2020. Management of poultry manure in Poland current state and future perspectives. Journal of Environmental Management 264: 110327.

De Smet, J., Wynants, E., Cos, P. and Van Campenhout, L., 2018. Microbial community dynamics during rearing of black soldier fly larvae (Hermetia illucens) and its impact on exploitation potential. Applied and Environmental Microbiology 84: e02722-17.

Erickson, M.C., Islam, M., Sheppard, C., Liao, J. and Doyle, M.P., 2004. Reduction of Escherichia coli O157:H7 and Salmonella enterica Serovar Enteritidis in chicken manure by larvae of the black soldier fly. Journal of Food Protection 67: 685-690.

Fang, W., Zhang, P., Gou, X., Zhang, H., Wu, Y., Ye, J. and Zeng, G., 2016. Volatile fatty acid production from spent mushroom compost: effect of total solid content. International Biodeterioration \& Biodegradation 113: 217-221.

Food and Agriculture Organisation (FAO), 2009. The state of food and agriculture 2009. Livestock in the balance. FAO Agriculture Series. FAO, Rome, Italy.

Fast, D., Kostiuk, B., Foley, E. and Pukatzki, S., 2018. Commensal pathogen competition impacts host viability. Proceedings of the National Academy of Sciences 115: 7099.

Hales, K.E., Parker, D.B. and Cole, N.A., 2012. Potential odorous volatile organic compound emissions from feces and urine from cattle fed corn-based diets with wet distillers grains and solubles. Atmospheric Environment 60: 292-297.

Huang, Y., Yu, Y., Zhan, S., Tomberlin, J.K., Huang, D., Cai, M., Zheng, L., Yu, Z. and Zhang, J., 2020. Dual oxidase duox and toll-like receptor 3 TLR3 in the toll pathway suppress zoonotic pathogens through regulating the intestinal bacterial community homeostasis in Hermetia illucens L. PLoS ONE 15: e0225873.

Isibika, A., Vinnerås, B., Kibazohi, O., Zurbrügg, C. and Lalander, C., 2019. Pre-treatment of banana peel to improve composting by black soldier fly (Hermetia illucens (L.), Diptera: Stratiomyidae) larvae. Waste Management 100: 151-160.

Jiang, C., Jin, W., Tao, X., Zhang, Q., Zhu, J., Feng, S., Xu, X., Li, H., Wang, Z. and Zhang, Z., 2019. Black soldier fly larvae (Hermetia illucens) strengthen the metabolic function of food waste biodegradation by gut microbiome. Microbial Biotechnology 12: 528-543.
Kamareddine, L., Robins, W.P., Berkey, C.D., Mekalanos, J.J. and Watnick, P.I., 2018. The Drosophila immune deficiency pathway modulates Enteroendocrine function and host metabolism. Cell Metabolism 28: 449-462.

Kim, E.K., Lee, K.A., Hyeon, D.Y., Kyung, M., Jun, K.Y., Seo, S.H., Hwang, D., Kwon, Y. and Lee, W.J., 2020. Bacterial nucleoside catabolism controls quorum sensing and commensal-to-pathogen transition in the Drosophila gut. Cell Host Microbe 27: 345-357.

Kivits, T., Broers, H.P., Beeltje, H., Van Vliet, M. and Griffioen, J., 2018. Presence and fate of veterinary antibiotics in age-dated groundwater in areas with intensive livestock farming. Environmental Pollution 241: 988-998.

Kogut, M.H., Lee, A. and Santin, E., 2020. Microbiome and pathogen interaction with the immune system. Poultry Science 99: 1906-1913.

Landers, T.F., Cohen, B., Wittum, T.E. and Larson, E.L., 2012. A review of antibiotic use in food animals: perspective, policy, and potential. Public Health Reports 127: 4-22.

Li, L., Stasiak, M., Li, L., Xie, B., Fu, Y., Gidzinski, D., Dixon, M. and Liu, H., 2016. Rearing Tenebrio molitor in BLSS: dietary fiber affects larval growth, development, and respiration characteristics. Acta Astronautica 118: 130-136.

Li, H., Wan, Q., Zhang, S., Wang, C., Su, S. and Pan, B., 2019a. Housefly larvae (Musca domestica) significantly accelerates degradation of monensin by altering the structure and abundance of the associated bacterial community. Ecotoxicology and Environmental Safety 170: 418-426.

Li, W., Ni, J., Cai, S., Liu, Y., Shen, C., Yang, H., Chen, Y., Tao, J., Yu, Y. and Liu, Q., 2019b. Variations in microbial community structure and functional gene expression in bio-treatment processes with odorous pollutants. Scientific Reports 9: 17870.

Liu, Q., Tomberlin, J.K., Brady, J.A., Sanford, M.R. and Yu, Z., 2008. Black soldier fly (Diptera: Stratiomyidae) larvae reduce Escherichia coli in dairy manure. Environmental Entomology 37: 1525-1530.

Liu, T., Awasthi, M.K., Awasthi, S.K., Duan, Y. and Zhang, Z., 2020. Effects of black soldier fly larvae (Diptera: Stratiomyidae) on food waste and sewage sludge composting. Journal of Environmental Management 256: 109967.

Liu, T., Kumar, A.M., Chen, H., Duan, Y., Awasthi, S.K. and Zhang, Z., 2019. Performance of black soldier fly larvae (Diptera: Stratiomyidae) for manure composting and production of cleaner compost. Journal of Environmental Management 251: 109593.

Ma, Y., Shen, Y. and Liu, Y., 2020. Food waste to biofertilizer: a potential game changer of global circular agricultural economy. Journal of Agricultural and Food Chemistry 68: 5021-5023.

Mazza, L., Xiao, X., ur Rehman, K., Cai, M., Zhang, D., Fasulo, S., Tomberlin, J.K., Zheng, L., Soomro, A.A., Yu, Z. and Zhang, J., 2020. Management of chicken manure using black soldier fly (Diptera: Stratiomyidae) larvae assisted by companion bacteria. Waste Management 102: 312-318.

Muloi, D., Ward, M.J., Pedersen, A.B., Fèvre, E.M., Woolhouse, M.E.J. and Van Bunnik, B.A.D., 2018. Are food animals responsible for transfer of antimicrobial-resistant Escherichia coli or their resistance determinants to human populations? A systematic review. Foodborne Pathogens \& Disease 15: 467-474. 
Peng, B., Su, Y., Chen, Z., Chen, J., Zhou, X., Benbow, M.E., Criddle, C.S., Wu, W. and Zhang, Y., 2019. Biodegradation of polystyrene by dark (Tenebrio obscurus) and yellow (Tenebrio molitor) mealworms (Coleoptera: Tenebrionidae). Environmental Science \& Technology 53: 5256-5265.

Qian, Y., Song, K., Hu, T. and Ying, T., 2018. Environmental status of livestock and poultry sectors in China under current transformation stage. Science of the Total Environment 622-623: 702-709.

Raza, M.F., Wang, Y., Cai, Z., Bai, S., Yao, Z., Awan, U.A., Zhang, Z., Zheng, W. and Zhang, H., 2020. Gut microbiota promotes host resistance to low-temperature stress by stimulating its arginine and proline metabolism pathway in adult Bactrocera dorsalis. PLoS Pathogens 16: e1008441.

Rosenfeld, P.E., Clark, J.J.J., Hensley, A.R. and Suffet, I.H., 2007. The use of an odour wheel classification for the evaluation of human health risk criteria for compost facilities. Water Science and Technology 55: 345-357.

Salihoglu, G., Salihoglu, N.K., Ucaroglu, S. and Banar, M., 2018. Food loss and waste management in Turkey. Bioresource Technology 248: 88-99.

Shi, N., Li, N., Duan, X. and Niu, H., 2017. Interaction between the gut microbiome and mucosal immune system. Military Medical Research 4: 14 .

Shin, N., Whon, T.W. and Bae, J.W., 2015. Proteobacteria: microbial signature of dysbiosis in gut microbiota. Trends in Biotechnology 33: 496-503.

Sindhu, R., Gnansounou, E., Rebello, S., Binod, P., Varjani, S., Thakur, I.S., Nair, R.B. and Pandey, A., 2019. Conversion of food and kitchen waste to value-added products. Journal of Environmental Management 241: 619-630.

Somroo, A.A., ur Rehman, K., Zheng, L., Cai, M., Xiao, X., Hu, S., Mathys, A., Gold, M., Yu, Z. and Zhang, J., 2019. Influence of Lactobacillus buchneri on soybean curd residue co-conversion by black soldier fly larvae (Hermetia illucens) for food and feedstock production. Waste Management 86: 114-122.

Spencer, J.L. and Guan, J., 2004. Public health implications related to spread of pathogens in manure from livestock and poultry operations. In: Spencer, J.F.T. and Ragout de Spencer, A.L. (eds.) Public health microbiology: methods and protocols. Humana Press, Totowa, NJ, USA, pp. 503-515.

Storelli, G., Defaye, A., Erkosar, B., Hols, P., Royet, J. and Leulier, F., 2011. Lactobacillus plantarum promotes Drosophila systemic growth by modulating hormonal signals through TOR-dependent nutrient sensing. Cell Metabolism 14: 403-414.

Ström, G., Albihn, A., Jinnerot, T., Boqvist, S., Andersson-Djurfeldt, A., Sokerya, S., Osbjer, K., San, S., Davun, H. and Magnusson, U., 2018. Manure management and public health: Sanitary and socioeconomic aspects among urban livestock-keepers in Cambodia. Science of the Total Environment 621: 193-200.

Sun, L., Pope, P.B., Eijsink, V.G.H. and Schnürer, A., 2015. Characterization of microbial community structure during continuous anaerobic digestion of straw and cow manure. Microbial Biotechnology 8: 815-827.
Sundberg, C., Yu, D., Franke-Whittle, I., Kauppi, S., Smårs, S., Insam, H., Romantschuk, M. and Jönsson, H., 2013. Effects of pH and microbial composition on odour in food waste composting. Waste Management 33: 204-211.

Tanaro, J.D., Pianciola, L.A., D’Astek, B.A., Piaggio, M.C., Mazzeo, M.L., Zolezzi, G. and Rivas, M., 2018. Virulence profile of Escherichia coli O157 strains isolated from surface water in cattle breeding areas. Letters in Applied Microbiology 66: 484-490.

Tyrrell, C., Burgess, C.M., Brennan, F.P. and Walsh, F., 2019. Antibiotic resistance in grass and soil. Biochemical Society Transactions 47: 477-486.

Udikovic-Kolic, N., Wichmann, F., Broderick, N.A. and Handelsman, J., 2014. Bloom of resident antibiotic-resistant bacteria in soil following manure fertilization. Proceedings of the National Academy of Sciences 111: 15202.

ur Rehman, K., Cai, M., Xiao, X., Zheng, L., Wang, H., Soomro, A.A., Zhou, Y., Li, W., Yu, Z. and Zhang, J., 2017a. Cellulose decomposition and larval biomass production from the co-digestion of dairy manure and chicken manure by mini-livestock (Hermetia illucens L.). Journal of Environmental Management 196: 458-465.

ur Rehman, K., Rehman, A., Cai, M., Zheng, L., Xiao, X., Somroo, A. Wang, H., Li, W., Yu, Z. and Zhang, J., 2017b. Conversion of mixtures of dairy manure and soybean curd residue by black soldier fly larvae (Hermetia illucens L.). Journal of Cleaner Product 154: 366-373.

ur Rehman, K., ur Rehman, R., Somroo, A.A., Cai, M., Zheng, L., Xiao, X., ur Rehman, A., Rehman, A., Tomberlin, J.K., Yu, Z. and Zhang, J., 2019. Enhanced bioconversion of dairy and chicken manure by the interaction of exogenous bacteria and black soldier fly larvae. Journal of Environmental Management 237: 75-83.

Urbanek, A.K., Rybak, J., Wróbel, M., Leluk, K. and Mirończuk, A.M., 2020. A comprehensive assessment of microbiome diversity in Tenebrio molitor fed with polystyrene waste. Environmental Pollution 262: 114281.

Van Huis, A., Van Itterbeeck, J., Klunder, H., Mertens, E., Halloran, A., Muir, G. and Vantomme, P., 2013. Edible insects: future prospects for food and feed security. Food and Agriculture Organization of the United Nations, Rome, Italy, pp. 59-61. Available at: http:// www.fao.org/docrep/018/i3253e/i3253e.pdf.

Wang, H., Sangwan, N., Li, H., Su, J., Oyang, W., Zhang, Z., Gilbert, J.A., Zhu, Y., Ping, F. and Zhang, H., 2017. The antibiotic resistome of swine manure is significantly altered by association with the Musca domestica larvae gut microbiome. The ISME Journal 11: 100-111.

Wanja, D.W., Mbuthia, P.G., Waruiru, R.M., Mwadime, J.M., Bebora, L.C., Nyaga, P.N. and Ngowi, H.A., 2020. Fish husbandry practices and water quality in central Kenya: potential risk factors for fish mortality and infectious diseases. Veterinary Medicine International 2020: 6839354.

Wang, H., Li, H, Gilbert J.A., Li, H., Wu, L., Liu, M., Wang, L., Zhou,Q., Yuan, J. and Zhang Z., 2015. Housefly larva vermicomposting efficiently attenuates antibiotic resistance genes in swine manure, with concomitant bacterial population changes. Applied and Environmental Microbiology 81: 7668-7679. 
Wynants, E., Frooninckx, L., Crauwels, S., Verreth, C., De Smet, J., Sandrock, C., Wohlfahrt, J., Van Schelt, J., Depraetere, S., Lievens, B., Van Miert, S., Claes, J. and Van Campenhout, L., 2019. Assessing the microbiota of black soldier fly larvae (Hermetia illucens) reared on organic waste streams on four different locations at laboratory and large scale. Microbial Ecology 77: 913-930.

Xiao, X., Mazza, L., Yu, Y., Cai, M., Zheng, L., Tomberlin, J.K., Yu, J., Van Huis, A., Yu, Z., Fasulo, S. and Zhang, J., 2018. Efficient co-conversion process of chicken manure into protein feed and organic fertilizer by Hermetia illucens L. (Diptera: Stratiomyidae) larvae and functional bacteria. Journal Environmental Management 217: 668-676

Xie, W., Shen, Q. and Zhao, F., 2018. Antibiotics and antibiotic resistance from animal manures to soil: a review. European Journal of Soil Science 69: 181-195.

Yan, C., He, W., Xue, Y., Liu, E. and Liu, Q., 2016. Application of biodegradable plastic film to reduce plastic film residual pollution in Chinese agriculture [in Chinese]. Sheng Wu Gong Cheng Xue Bao 32: 748-760.

Yang, J., Yang, Y., Wu, W., Zhao, J. and Jiang, L. 2014. Evidence of polyethylene biodegradation by bacterial strains from the guts of plastic-eating waxworms. Environmental Science Technology 48: 13776-13784.

Yang, S., Xie, J., Hu, N., Liu, Y., Zhang, J., Ye, X. and Liu, Z., 2015. Bioconversion of gibberellin fermentation residue into feed supplement and organic fertilizer employing housefly (Musca domestica L.) assisted by Corynebacterium variabile. PLoS ONE 10: e0110809.

Yang, Y., Wang, J. and Xia, M., 2020. Biodegradation and mineralization of polystyrene by plastic-eating superworms Zophobas atratus. Science of the Total Environment 708: 135233.

Yao, Y., Zhu, F., Hong, C., Chen, H., Wang, W., Xue, Z., Zhu, W., Wang, G. and Tong, W., 2020. Utilization of gibberellin fermentation residues with swine manure by two-step composting mediated by housefly maggot bioconversion. Waste Management 105: 339-346.
Yu, G., Cheng, P., Chen, Y., Li, Y., Yang, Z., Chen, Y. and Tomberlin, J.K., 2011. Inoculating poultry manure with companion bacteria influences growth and development of black soldier fly (Diptera: Stratiomyidae) larvae. Environmental Entomology 40: 30-35.

Zhan, S., Fang, G., Cai, M., Kou, Z., Xu, J., Cao, Y., Bai, L., Zhang, Y., Jiang, Y., Luo, X., Xu, J., Xu, X., Zheng, L., Yu, Z., Yang, H., Zhang, Z., Wang, S., Tomberlin, J.K., Zhang, J. and Huang, Y., 2020. Genomic landscape and genetic manipulation of the black soldier fly Hermetia illucens, a natural waste recycler. Cell Research 30: 50-60.

Zhang, K., Hu, R., Cai, M., Zheng, L., Yu, Z. and Zhang, J., 2017. Degradation of plastic film containing polyethylene (PE) by yellow meal worms. Chemistry and Bioengineering 34: 47-49.

Zhang, L., Li, L., Pan, X., Shi, Z., Feng, X., Gong, B., Li, J. and Wang, L., 2018. Enhanced growth and activities of the dominant functional microbiota of chicken manure composts in the presence of maize straw. Frontier Microbiology 9: 1131.

Zhang, M., He, L., Liu, Y., Zhao, J., Zhang, J., Chen, J., Zhang, Q. and Ying, G., 2020. Variation of antibiotic resistome during commercial livestock manure composting. Environment International 136: 105458.

Zhang, Z., Wang, H., Zhu, J., Suneethi, S. and Zheng, J., 2012. Swine manure vermicomposting via housefly larvae (Musca domestica): the dynamics of biochemical and microbial features. Bioresource Technology 118: 563-571.

Zheng, H., Perreau, J., Powell, J.E., Han, B., Zhang, Z., Kwong, W.K., Tringe, S.G. and Moran, N.A., 2019. Division of labor in honey bee gut microbiota for plant polysaccharide digestion. Proceedings of the National Academy of Sciences 116: 25909.

Zheng, H., Powell, J.E., Steele, M.I., Dietrich, C. and Moran, N.A., 2017. Honeybee gut microbiota promotes host weight gain via bacterial metabolism and hormonal signaling. Proceedings of the National Academy of Sciences 114: 4775. 